\title{
ESTUDOS LINGUÍSTICOS, HUMOR, POLÍTICA E ENSINO DE LÍNGUA ${ }^{1}$ \\ Entrevista com Sírio Possenti
}

Linguistics Studies, humor, politics and Language education

\author{
Entrevista com Sírio Possenti ${ }^{2}$ \\ Universidade Estadual de Campinas - UNICAMP
}

\begin{abstract}
RESUMO: Nesta entrevista, o linguista e professor Sírio Possenti aborda alguns dos temas a que se dedica em suas pesquisas, nos apresentando as contribuições que outros campos de estudo trouxeram para os estudos linguísticos, como aquelas provenientes da Filosofia. Ele também trata das relações entre o humor, a mídia e a política, de uma perspectiva discursiva, e finaliza discutindo a importância dos conhecimentos científicos sobre a língua e a linguagem para o ensino de língua portuguesa no Brasil.
\end{abstract}

Palavras-chave: Linguística; Filosofia; Humor; Ensino de língua.

ABSTRACT: In this interview, the linguist and professor, Sírio Possenti, resumes some of the themes he dedicates to his research, presenting us the contributions that other fields to linguistic studies, such as those from Philosophy. It also presents his researches about humor, the media and politics, from a discursive perspective, and ends by discussing the importance of the advances in linguistic knowledge for language education in Brazil.

Keywords: Linguistics; Philosophy; Humor; Language education.

\footnotetext{
${ }^{1}$ Entrevista realizada no dia 14 de setembro de 2018 durante o V CIAD - Colóquio Internacional de Análise do Discurso: Discurso e (pós)verdade. Efeitos de real e sentidos da convicção. Na ocasião, o entrevistado proferiu a conferência "A verdade onde poderia não ser chamada". A equipe responsável pela produção, transcrição, retextualização e revisão desta entrevista foi composta por Evandro Paschoalino, João Victor Dantas, Raquel Casare, Paula Zangrossi, Stephani Izidro e Vitória Castilho, discentes no curso de Bacharelado em Linguística da UFSCar, e Luzmara Curcino, docente no Departamento de Letras e no Programa de Pósgraduação em Linguística da Universidade Federal de São Carlos (DL/PPGL/UFSCar). A entrevista contou ainda com o apoio técnico de Daniel P. Graciano, Lívia Damaceno e Bianca Moreira Lopes.

${ }^{2}$ Doutor em Linguística e professor livre-docente na UNICAMP. Atua nas áreas de Teoria e Análise Linguística e é especialista em Análise do Discurso, dedicado, entre outros, ao estudo do campo do humor assim como dos modos como estudos da língua são (ou não) abordados na mídia. Entre suas principais publicações, destacamos os livros Discurso, estilo e subjetividade (1993); Por que (não) ensinar gramática na escola (1996) e Humor: Lingua e Discurso (2010).
} 


\section{Contribuições da Filosofia aos estudos linguísticos}

Entrevistadores: Além de sua formação como linguista, especialista em Análise do Discurso, em sua formação inicial a Filosofia teve um papel relevante. Que contribuições a Filosofia pode trazer para os estudos da linguagem e para o campo da Linguística?

Sírio Possenti: Há uma questão interessante sobre a relação da Linguística com outros campos de conhecimento vizinhos. Quando Saussure propôs uma teoria linguística - o que muitos consideram a sua fundação -, o que ele fez foi exatamente o contrário. Para tratar da língua como objeto científico ele retirou tudo aquilo que não seria linguístico, ou seja, todos os pontos de vista que se avizinhavam de questões da língua, como a psicologia, a história e a geografia, afirmando que tudo isso era secundário porque tinham mais a ver com a fala, e não com a língua.

Acontece que os estudos da linguagem não pararam por aí. Um dos acontecimentos fundamentais nesses estudos foi a virada filosófica ou a virada pragmática. Essa mudança consistiu em não apenas considerar a Lógica, uma espécie de auxiliar dos estudos da Semântica formal, ou a Semântica vericondicional, dedicada a estudar se uma asserção é verdadeira ou se é falsa, a estudar a questão da referência etc., mas também e sobretudo a considerar o estudo do sentido da linguagem ordinária. O interesse então se volta a responder questões como: 'O que significa dar uma ordem?'. É interessante o exemplo de Robin Lakoff $^{3}$ : "Você tem que provar este pastel!". Com ele, se demonstra como a estrutura própria de uma ordem pode servir para que se formule um convite, uma oferta, um elogio ao pastel.

Acredito que os estudos de Pragmática foram os que mais se beneficiaram dos conhecimentos da Filosofia, em especial aqueles dedicados a descrever o funcionamento da linguagem comum, dita ordinária. Não da linguagem científica, ou da lógica, ou da metafísica, ou melhor, da linguagem referencial, mas da linguagem como uma prática exercida entre interlocutores em situação social específica. Também, a Análise do Discurso, na esteira de Michel Pêcheux ${ }^{4}$, mostra que a língua não é esse sistema autossuficiente e que a história é importante para os sentidos que por meio de usos são produzidos. O débito da Análise do Discurso com a Filosofia é bastante grande e valeria a pena ler determinados filósofos, especialmente os marxistas, como Louis Althusser ${ }^{5}$, porque eles, entre outras

\footnotetext{
${ }^{3}$ Cf. Lakoff (1972). É um exemplo de ato de fala indireto, cujo sentido é obviamente não literal.

${ }^{4}$ Cf. Pêcheux $(2014 ; 2019)$.

${ }^{5}$ Cf. Althusser (1998).
} 
reflexões, questionaram o tema da 'consciência' do sujeito que fala e também porque respondem por uma tradição filosófica muito importante. Portanto, acho que a Filosofia é uma vizinha cuja amizade deve ser cultivada, uma vizinha interessante para os estudos linguísticos.

\section{Humor e seu papel político}

Entrevistadores: Um dos temas importantes de suas pesquisas é o humor. Por que o interesse pelo humor? Há alguma especificidade dos textos humorísticos quanto ao funcionamento da autoria, por exemplo?

Sírio Possenti: A respeito do humor, eu tenho defendido ultimamente que ele é uma espécie de 'campo', e por isso atua como uma instância que circunscreve as práticas, inclusive profissionais: alguém é humorista em certa parte do tempo, em outra é advogado. Trata-se, portanto, de um campo, que conta com regras próprias, uma das quais é tratar das coisas de um modo que não pareça ser sério. Em princípio, o humorista diz coisas que quando confrontadas com a verdade são falsas, não são verdadeiras, sobretudo em sua generalização. Não é verdade, por exemplo, que maridos traem suas esposas, que o político é ladrão, ou que determinado grupo étnico é pão duro, tal como se enuncia nas piadas de turco que usam esse estereótipo, e assim por diante. O humor não tem compromisso com a verdade. Ele tem compromisso com um certo jogo de oposições entre o que é sério e o que não é sério.

O que é importante no humor é que ele é uma espécie de passagem de um espaço para outro, ou seja, uma piada é como uma historinha que começa como se fosse verdadeira e em um certo momento explora-se um jogo de palavras, o que impõe uma inflexão dessa condição, de modo que não se pode mais interpretar aquilo que foi narrado como algo sério, mas sim de um modo jocoso. Frequentemente, em sua interpretação é preciso descobrir o implícito, ou seja, aquilo que não está dito efetivamente, mas pressuposto, e que uma vez identificado, surpreende por não fazer parte do desenvolvimento daquela história, segundo a sua versão mais comum, mais típica, ou mais prototípica.

O humor tem muito a ver com a surpresa e com o exagero. Por exemplo, tem uma charge intitulada "Coice presidencial", que traz como legenda o título de matéria publicada em um portal de notícias "Presidente chama de 'idiota' pergunta feita sobre uso de helicóptero da FAB no casamento do seu filho", em que se mostra parcialmente um cavalo dando coices, dando patadas, em direção a um conjunto de microfones. 
Figura 1 - "Coice Presidencial”, de Sidney Falcão ${ }^{6}$

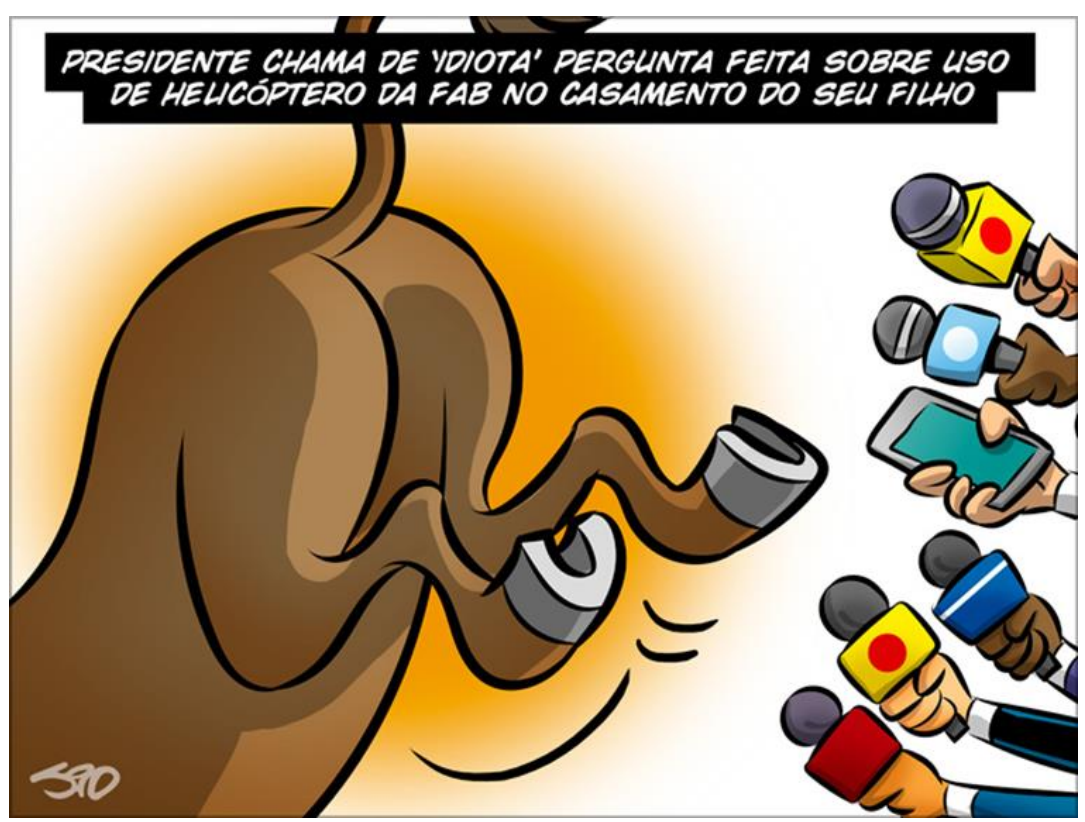

Fonte: Blog Feijoada Visual.

O que é responsável pelo efeito de humor, nesse caso, para além da questão ideológica, é o exagero da metáfora. Como ele é grosseiro e rude quando fala, sobretudo quando interpelado incisivamente pela imprensa, ele é mostrado como um cavalo dando patadas de modo a simbolizar essa grosseria por meio de uma representação exagerada. É esse exagero que produz o efeito de humor, graças à surpresa, à exploração de duplo sentido, de jogo de palavras, de implícitos.

\section{Humor, verdade e mentira}

Entrevistadores: Nesses tempos de ampliação das técnicas e dos meios tecnológicos de produção e de circulação dos textos, vemos emergir uma série de textos que exploram deliberadamente a mentira e a fazem circular como se fosse uma verdade. Como a produção do humor contribui tanto para a propagação quanto para a crítica dessas convicções pessoais sem lastro e dessa lógica da desinformação estratégica?

Sírio Possenti: O humor, em certo sentido, é como os outros gêneros do discurso. Diante de uma piada que pareça ser uma crítica a um determinado grupo político, pode-se achar que ela

\footnotetext{
6 Charge de Sidney Falcão publicada em 28 de julho de 2019. Disponível em:
} <https://sidneyfalcao.blogspot.com/2019/07/coice-presidencial.html>. Acesso em: 12 jan. 2020. 
é interessante, engraçada, se se for partidário da mesma crítica, ou que ela é de mau gosto, sem graça se se identificar com o grupo criticado. Às vezes, os leitores reclamam porque o jornal publicou uma charge contra um político, ou que o chargista o faz repetidas vezes, e perguntam o porquê de não se publicar também charges de mesmo teor sobre os outros políticos. Isso acontece porque talvez não haja humoristas que queiram criticar os outros políticos, ou seja, os chargistas que estão por aí, que atuam nesses jornais e revistas se alinham ideologicamente na crítica a um ou aos demais políticos de um certo grupo. Isso mostra como uma piada, uma charge ou uma notícia reproduzem um certo sentido, visando a um mesmo efeito. Diante desses textos, pode-se aderir a seu ponto de vista ou entender que aquela charge é uma crítica ao meu candidato, do que deriva o descontentamento com ela e a crítica de que ela é injusta ou exagerada. Se é uma notícia desfavorável ao meu candidato, a tendência é eu suspeitar de que ela foi distorcida ou que é exagerada.

Nesse sentido, acredito que o humor não diz nada de novo ou diferente de outros gêneros. Ele retoma algo conhecido e o apresenta em uma nova linguagem. $O$ humor não inventa nada, ele exagera e intensifica. Por exemplo, aquela charge sobre o Bolsonaro, a que me referi anteriormente, não é de autoria de alguém que, de maneira casual, procuraria aquele de que vai fazer a crítica, o cumprimentaria e avisaria que faria uma charge crítica a seu respeito: "Prazer, Bolsonaro, vou fazer uma charge sua". Considerando que o humor de uma charge se deve, entre outras características, ao tipo de estereótipo explorado e ao exagero em relação ao comportamento daquele que se critica, logo, a charge não inventa nada de novo sobre o personagem e seu comportamento, ela apenas recorre aos estereótipos e ao exagero na sua representação. Poderia se dizer que o que se inventou nessa charge sobre o Bolsonaro foi apenas a analogia com o cavalo. Em outras charges com o mesmo objetivo referentes à mesma crítica poderiam representá-lo enfurecido, xingando, gesticulando com a mão como se tivesse uma arma. Nesta, no entanto, decidiu-se representar seu gesto como o de um cavalo, explorando uma imagem de domínio comum, uma metáfora bastante conhecida de todos nós.

Portanto, existe uma inventividade, mas não propriamente no conteúdo. Assim, o humor não é em si propagador ou desmistificador de desinformação. Ele até tem sido mobilizado mais como forma de crítica, não por uma novidade quanto ao que se diz (conteúdo), mas sim quanto ao modo peculiar de dizer (forma).

Embora a forma, no humor, seja fundamental, não se pode perder de vista que forma e conteúdo sempre estão juntos. Quando é a forma que prepondera, como no caso dos textos de humor, significa que o conteúdo é um objeto de interpretação, em relação ao qual pode haver muita discordância. Quando o conteúdo é dominante, discute-se a forma. Exemplo disso, é 
que ouvimos e nos expressamos nos seguintes termos: "Tá bom. Isso que está dito é verdade. Mas também não é preciso exagerar.”. Há sempre um jogo entre forma e conteúdo, e no caso do humor este jogo está muito vinculado com o implícito. O que se quis dizer com essa charge que, para se referir ao comportamento de Bolsonaro em entrevista com os jornalistas, representa um cavalo dando coices, mas que não está enunciado explicitamente?

Um outro exemplo desse tipo de analogia, de sugestão e de exagero pode ser encontrado na charge de Laerte, intitulada "Perspectiva de governo", que alude pela imagem uma reunião ministerial, de políticos do legislativo ou executivo, em que todos usam tornozeleira eletrônica.

Figura 2 - "Perspectiva de governo", de Laerte

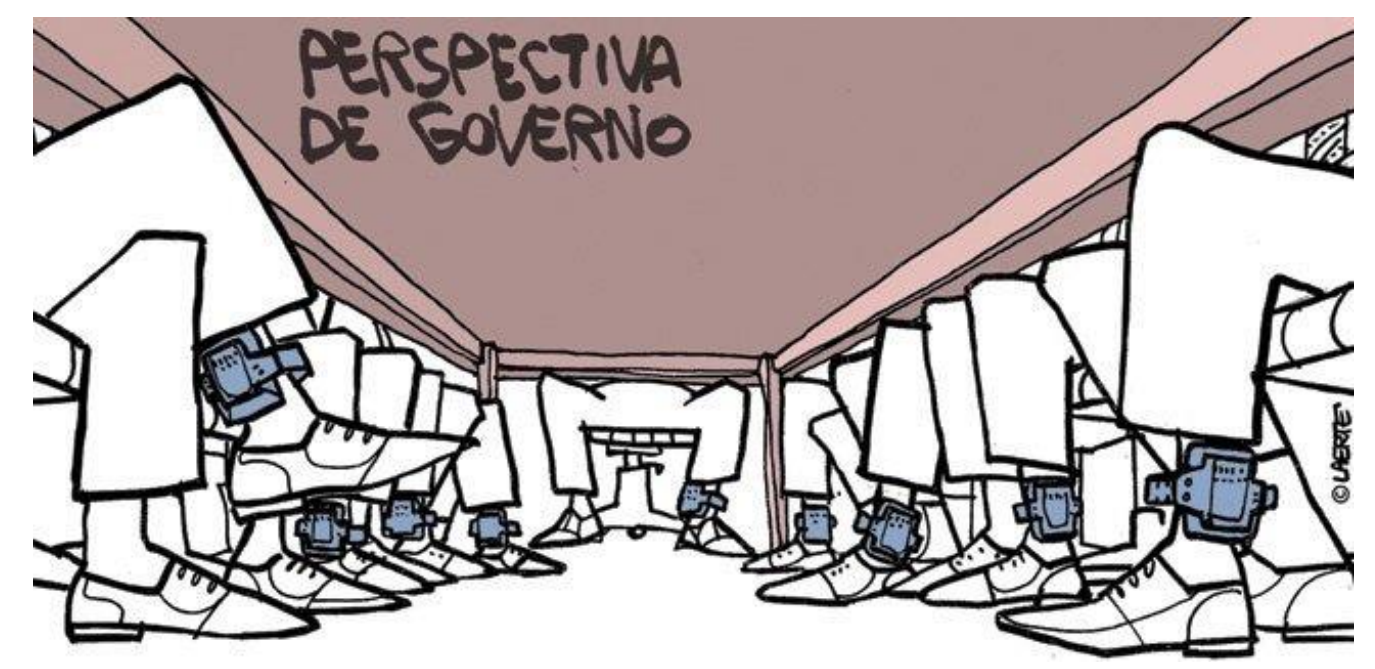

Fonte: Folha de S. Paulo, 21 jun. 2016.

Isso quer dizer o quê? Que todos são ladrões? Ou que todos eles são condenados, mas não estão presos? Dá para fazer um debate sobre isso porque é um texto que tem uma abertura, uma possibilidade de interpretações, embora não qualquer uma, ou seja, aberta até certo ponto. Além dele, não. Por exemplo, não se pode achar que os chargistas nesses exemplos estão representando esses 'caras' como anjos, mas como gente com tornozeleira. Existe uma memória acerca de quem usa tornozeleira, e é a partir dessa memória que interpretamos: “Ah, sim! Fulano está dizendo que os ministros do atual governo são todos criminosos, ou que eles não deveriam estar governando e sim que mereceriam estar na cadeia!". 


\section{Estudos linguísticos e ensino da escrita e da leitura}

Entrevistador: Parte de sua significativa produção acadêmico-científica foi dedicada à difusão dos conhecimentos linguísticos e suas contribuições para o ensino de língua. Faz parte dos clássicos da linguística brasileira seu livro Por que (não) ensinar gramática na escola. Poderia discorrer brevemente sobre o papel da Linguística em relação ao ensino de língua?

Sírio Possenti: Essa é uma questão fundamental. Os estudos linguísticos já demonstraram que há várias mudanças importantes pelas quais o ensino de língua poderia passar. Uma delas já deveria ter sido implementada de vez, relativa à superação do preconceito linguístico. A ciência linguística, os saberes linguísticos já demonstraram não haver nenhuma razão lógica, científica que justifique o preconceito linguístico. Os linguistas já demonstraram que as formas populares de expressão não são piores ou melhores que as formas padrão ou cultas de expressão. Eventualmente, uma forma popular do português brasileiro é estruturalmente igual a uma forma popular do inglês, e, dada a força do preconceito linguístico, essa semelhança ou não é reconhecida ou apenas se concede o acerto à versão em inglês. Se são fenômenos semelhantes, então, por que a norma popular brasileira seria ruim? Por que no português ela é considerada precária e no inglês, adequada?

Se nós conseguíssemos superar esse preconceito contra os falares populares, considerados errados, insuficientes, precários e pobres, acredito que as escolas e o seu ensino poderiam mudar de patamar, especialmente as escolas que abrigam esses alunos vindos de classes populares, que eventualmente a própria escola considera incapazes, em alguns casos patologizando as dificuldades de aprendizagem desses alunos, e encaminhando-os a psicólogos ou fonoaudiólogos com um pré-diagnóstico de dislexia, disgrafia, e assim por diante. Na verdade, esse não é o problema. Eles apenas nasceram pobres, nasceram na roça, por exemplo, e por isso falam diferentemente da variedade padrão. A ciência linguística demonstra que tais alunos não têm nenhum déficit linguístico, muito menos cognitivo, e essa é uma contribuição fundamental das ciências da linguagem para o ensino em um país como o Brasil, onde metade da população, ou mais, faz uso dessa variedade popular.

\section{Da Intersecção de Discursos de campos distintos}

Entrevistador: A que o professor tem se dedicado em suas pesquisas mais recentemente? 
Sírio Possenti: Meu projeto de pesquisa mais recente foi inicialmente pensado como um projeto de análise de texto, de leitura e de descrição de como o texto se apresenta, identificando em que medida nesses textos se pode mobilizar ideologias ou crenças de tal modo que o texto se apresente como filosófico ou científico. Um exemplo disto é a "Carta dos Direitos Humanos", que não se pretende como um discurso científico. No entanto, ao delimitar direitos e deveres, recorre à filosofia. Essa carta se mostra assim, e de tal modo, que homens mobilizados por certas crenças acreditam ser um projeto em prol da humanidade. $\mathrm{O}$ meu interesse se centra em verificar o momento em que aquilo que um dado texto enuncia se fortalece, ao evocar e se valer do discurso científico como justificativa.

Para que se acredite, por exemplo, que todos os homens são iguais, é necessário mostrar, por exemplo, que os negros, os brancos e os amarelos têm o mesmo QI. Quando alguém diz: "eu fiz testes e demonstrei que os amarelos são mais inteligentes que os brancos", está usando a ciência, o discurso científico, para estabelecer uma distinção entre os humanos, uma distinção baseada numa crença não-científica, mas que se apresenta na formulação como se fosse. Portanto, o que está me interessando neste momento é verificar quando é que um discurso como o científico é evocado para justificar uma tese em um texto que não necessariamente é uma tese científica.

Outro exemplo são os textos que falam da Reforma da Previdência. Evoca-se neles um conhecimento de tipo científico a respeito da população brasileira. Afirma-se, por exemplo, com base em um conjunto de dados estatísticos, que a população está envelhecendo, para justificar a necessidade de modificação das regras da Previdência, argumentando que o montante de dinheiro captado hoje terá de pagar mais aposentadorias do que pagava antes; logo, as pessoas não podem mais se aposentar na idade em que se aposentam hoje. É preciso que aguardem mais. Por exemplo, até os 65 anos ou mais.

A argumentação em textos desse tipo se vale de uma tese, digamos, científica, ou quase científica, para justificar uma posição ideológica. Também é ideológica, não podemos esquecer, a decisão segundo a qual um idoso deve receber uma aposentadoria, ser mantido vivo pela coletividade, pelo Estado, em função de suas ações em prol dessa coletividade, quando se poderia ter uma civilização em que fosse normal dizer: "Viveu até os 70 anos, tudo bem, mas depois dessa idade nós devemos jogar todos estes idosos do precipício."

Esse tipo de posição foi explorado em um episódio da série de desenho animado da “Família Dinossauro". Nesse episódio se comemora "O dia do arremesso". É uma antiga tradição, segundo a qual, ao se completar 72 anos de idade, todo dinossauro idoso deveria ser jogado em um poço, para não ser um 'peso' para a família. É um tipo de ideologia, de cultura. 
Alguém poderia perguntar por que não poderíamos, nós também, agir assim ${ }^{7}$ ? Podemos responder a isso dizendo que é em razão de uma "ideologia".

Nós acreditamos que todo mundo tem direito à vida, independentemente de ser jovem ou idoso. Essa é, no fundo, a mesma tese de quem é contra o aborto. Para estes, o feto já é vida, portanto, não se pode abortar. Essa é uma tese ideológica, seja ela religiosa, política, filosófica. Do ponto de vista econômico, se poderia dizer: "É mais barato para uma família o aborto, porque seria uma boca a menos para alimentar”. Essa não é, no entanto, a questão. A questão é outra. É ética, moral, filosófica, religiosa. Assim, para se defender uma tese religiosa, se poderia inclusive evocar a ciência. Pode-se, por exemplo, evocar a genética para afirmar que: "desde a fecundação se tem a vida, que a conjunção do óvulo com o espermatozoide já produz vida, e quando as células se separam já se tem um organismo vivo". Há pessoas que acreditam que ali ainda não se tem uma vida, um humano, e que só se torna um humano quando aquele organismo tiver algo parecido com o cérebro e com funcionamento cerebral. Este, aliás, é o critério para se definir a morte no Brasil. Quando não tem mais atividade cerebral, para a medicina, a pessoa é considerada morta. Foi com base nessa analogia para caracterizar o que é a vida que vários ministros do Supremo sustentaram sua decisão de tornarem legal a possibilidade de interromper a gravidez no caso em que o feto fosse diagnosticado como anencéfalos. Assim, se não tem cérebro, não tem vida humana. Mas outros podem argumentar diferentemente: “Ah, mas mesmo sem cérebro, é ainda uma vida humana. Essa pessoa só não vai ter condição de fazer certas coisas. Mas quem disse que é preciso fazer?".

Com esse tipo de afirmação, estamos no domínio da crença, da moral, da ética, da ideologia. Não se está mais no domínio da ciência propriamente dita. Mas a ciência, o discurso científico, tem servido tanto para se justificar uma posição quanto a outra.

Por isso tenho me interessado pela leitura de diferentes temas em textos publicados em jornais de modo a buscar identificar que discursos são evocados e de que modo: se o que se defende é em parte do âmbito da crença, também se apela para a geografia, para a medicina etc. para justificar teses. Por exemplo, em um texto, ao se dizer que comer muito sódio eleva a pressão e a pressão alta pode matar, se está evocando a ciência, não a crença, ou a questão do sabor, porque em matéria de sabor uma comida pode ser ótima, mas é ótima também para matar... É essa intersecção de discursos o que tem me interessado ultimamente.

\footnotetext{
${ }^{7} \mathrm{O}$ coronavírus fez circular teses do tipo "temos que sacrificar os mais velhos para salvar os mais jovens" ao lado de outras que rezam que qualquer vida é uma vida, vale o mesmo que outra.
} 


\section{Referências}

ALTHUSSER, Louis. Aparelhos Ideológicos de Estado. Rio de Janeiro: Editora Graal, 1998.

FOUCAULT, Michel. A arqueologia do saber. Rio de Janeiro: Editora Forense, 1986.

LAKOFF, Robin. El lenguaje en su entorno. In: FILLMORE, Charles et al. Semántica y sintaxis. Madrid: Aliana Editorial, 1972, p. 403-435.

PÊCHEUX, Michel. Análise Automática do Discurso. Campinas: Editora Pontes, 2019.

PÊCHEUX, Michel. Semântica e Discurso: uma crítica a afirmação do óbvio. Campinas: Editora da UNICAMP, 2014.

Recebido em: 12 de fevereiro de 2020.

Aceito em: 17 de abril de 2020. 